\title{
TRADING BASED ON KNOWING THE WASDE REPORT IN ADVANCE
}

\author{
TRENT T. MILACEK* \\ Department of Agricultural Economics, Oklahoma State University, Stillwater, Oklahoma \\ B. WADE BRORSEN \\ Department of Agricultural Economics, Oklahoma State University, Stillwater, Oklahoma
}

\begin{abstract}
Past research shows that prices move in response to World Agricultural Supply and Demand Estimates (WASDE) reports immediately prior to and after a report. This research develops trading models based on knowing the next WASDE report in advance. This should help traders evaluate investments to predict information contained within the report and in determining how best to use such forecasts. The price-forecasting models use regressions against the ratios of ending stocks to use. Results show a steady increasing return to trading over the report month. The highest returns are produced by trading during the growing and harvest seasons.
\end{abstract}

Keywords. Corn, ending stocks, forecasting, soybeans, speculation, WASDE

JEL Classifications. C53, G13, Q10

\section{Introduction}

At the end of the movie Trading Places, the two protagonists trade in frozen concentrated orange juice futures based on a stolen crop report. In their case, it was easy to know how to trade based on the report. However, that is not always the case. The U.S. Department of Agriculture (USDA) releases monthly World Agricultural Supply and Demand Estimates (WASDE), which contain fundamental market information such as the National Agricultural Statistics Service (NASS) crop production reports and ending stocks estimates. Private firms attempt to predict the WASDE reports using satellite imagery, publicly known supply-and-demand estimates, experimental plots, crop tours, and calls to grain firms, as well as many other ways to gather fundamental information (Milonas, 1987).

The research was supported by the A.J. and Susan Jacques Chair, the Oklahoma Agricultural Experiment Station, and U.S. Department of Agriculture, National Institute of Food and Agriculture Hatch project OKL02939.

*Corresponding author’s e-mail: trent.milacek@okstate.edu 
We develop trading models based on knowing the WASDE report in advance. The results allow estimating the potential trading returns using WASDE report predictions in the days before the report. Thus, the research provides a benchmark model for firms engaged in forecasting prices and estimates of potential per contract returns for firms considering investment in endeavors to predict the crop reports. Because any private forecasts would have errors, the results give an upper bound on what could be earned using private forecasts. Many agricultural economists have studied the effects of USDA crop production reports on commodity prices. Findings by Adjemian (2012), Fortenbery and Sumner (1993), Isengildina, Irwin, and Good (2006b), Isengildina-Massa et al. (2008a, 2008b), McKenzie (2008), Milonas (1987), Dorfman and Karali (2015), and Sumner and Mueller (1989) confirm that WASDE reports contain significant fundamental market information that causes market prices to change after the reports are released. The present research adds to this literature by showing how and when portions of the crop supply/demand information in the reports are reflected in market prices in advance of the reports.

WASDE reports are released on a monthly basis and contain information compiled by several USDA agencies such as NASS; the reports offer information on supply and demand and contain two main components, acres to be harvested and expected yield per acre (Vogel and Bange, 1999). The NASS crop production report and the WASDE report are developed secretly and are usually released between the 9th and 12th of every month (Vogel and Bange, 1999). For the 2000 crop, for example, the corn and soybean ending stocks in the WASDE reports are for the end of the crop year on September 1, 2001. The monthly reports that we consider for the 2000 crop year begin with projections in May 2000 and end in March 2001. According to the first report (USDA, 1973), these projections are meant to serve as guideline approximations based on the information currently known. Projections vary with every new report as crop, weather, and economic conditions change. Prices move after these reports are released because the information remains secret until the official report is released. The USDA fiercely guards this information to ensure that nothing is leaked before the report date (Vogel and Bange, 1999).

Price movements are larger following USDA reports (Isengildina, Irwin, and Good, 2006b). Similarly, Isengildina-Massa et al. (2008a, 2008b) found that after WASDE reports containing NASS crop production reports were released, implied volatility in corn and soybean markets was reduced. Sumner and Mueller (1989) found that the harvest forecast reports released in the months of August, September, and October cause a greater change in corn and soybean market prices than other reports. Known periods of greater market realignments offer traders a chance to capitalize on market movements. Adjemian (2012) also found that information from WASDE reports moved prices, especially those that contained NASS crop production reports. Private agencies already release 
prediction data in the days prior to a USDA report (McKenzie, 2008). If these forecasts encompassed the information in the WASDE reports and in turn negated the need for WASDE reports, the release would have no effect on price volatility. This is clearly not the case.

A few notable price forecasting models have been developed to predict grain prices based on information in the WASDE reports. Anderson and Tweeten (1975), Dunn (1975), Westcott and Hull (1985), Westcott and Hoffmann (1999), and Do (2010) all used variations of a regression of price against ending stocks or a stocks-to-use ratio. The model estimated by Do used more recent data, which yielded a lower $R$-squared for the regression than did Anderson and Tweeten (1975). Do's findings suggest that there has been structural change. More than a third of the U.S. corn crop is being used in ethanol production (Mallory, Irwin, and Hayes, 2012), which could create a structural change in the relationship between prices and ending stocks. Westcott and Hull (1985) and Westcott and Hoffmann (1999) find market relationships varied with different periods of government legislation. To predict prices, we develop a forecasting model than can quickly adjust to structural changes by using only recent data to calibrate the model.

Previous literature has shown the effects of WASDE reports on prices immediately after the report release. However, past literature has not considered models of how to use predictions to trade. This research considers trading of U.S. corn and soybean commodities spanning the crop years 1975-2012. Trading is simulated on a daily basis. Information provided includes seasonality of monthly trading returns and evidence regarding structural change in the relationship between prices and ending stocks. This research successfully fills a void in the current literature and serves as a relevant guide to the potential profitability of trading based on WASDE report information.

\section{WASDE Reports}

The WASDE reports are released on a monthly basis and contain information for many different agricultural commodities. They include information at the U.S. and world levels to provide information on the current supply of commodities and expected acreage and yield data. The WASDE report releases part of its information as projections and part as estimates. We use only projections. The projections can change as more information about economic conditions, availability of inputs, and crop and weather conditions are reported. Each new WASDE contains a new projection that represents the most current information gathered during that report month. The projections generally begin between May and April; the exception is the early WASDE reports from 1973 through 1979. During this time period, there was not a standard in which the projection year began, which allowed it to vary among the early months in the calendar year. All trading is in the March futures contract. A single expiration month is used so 
that the regression model is always predicting the same price. The only month of the calendar year that would not report returns is April because of the March contract expiration and a new WASDE report for the next contract year not becoming available until May.

The WASDE periodically releases reports that contain corrections for previous WASDE information. These corrections are generally issued soon after an initial report and show a small difference in the previously reported numbers and do not provide a large amount of new information to the market. As such, these reports were not included. Of the 533 WASDE reports released from September 17, 1973, to March 8, 2013, that contained U.S. corn projections, 38 contained corrections to corn ending stocks, and the ending stocks changed on average by $4.24 \%$ of the original value. The largest changes from the corrections occurred in WASDE reports that were released in the 1970s.

Insengildina, Irwin, and Good (2006a) provide evidence that when a large adjustment in a previous prediction is needed, the adjustment is not fully made in the next report, and thus projections are smoothed. Such smoothing could reduce the accuracy of our forecasts if the market responded to the true expected values rather than the smoothed reported values. Prices are not deflated because of the short estimation period and the lack of clear theory about what index to use.

The number of observations between WASDE reports can vary depending on the days that the WASDE reports are released. Because of the varying calendar days each month and the untimely release of various WASDE reports, the number of days between reports varies. Observations more than 31 calendar days are not considered because there are too few of them to be representative. Months are crop reporting months, and years are WASDE projection years (for example, 1975 is the $1974 / 75$ crop year).

\section{Forecasting Models}

Like past research, the key forecasting tool is a regression of price against ending stocks to use. However, past ending stocks regressions have used annual models. Here, we use monthly data and regress the futures price following the report against the projected ending stocks to use from the WASDE report. The models are reestimated for each report so that projections are out of sample from the estimation. Projections are made using the true ending stocks from the next WASDE report. Either a short or long position is always held. Trading returns are calculated daily and are based on settlement prices. The simulated trading holds a long (short) position when the settlement price is below (above) the price forecast. Two different regression approaches are used. The weighted average model uses a weighted average of the regression coefficients using previous reports on this crop year and the regression coefficients using last year's data. The weights are linearly adjusted based on the number of observations in the current crop year. Once 
10 observations are available, only the current crop year is used. The intuition behind the approach is to place more weight on the most current data and to give equal weight to data within a crop year. The rolling regression uses data from a set number of recent months to estimate the regression used to forecast prices. The alternative amounts of data used in the rolling regression are 12, 24, 35, 48, and 60 months.

Similar to previous literature (Anderson and Tweeten, 1975; Do, 2010; Irwin and Good, 2016; Westcott and Hoffmann, 1999; Westcott and Hull, 1985), price forecasts are obtained by regressing price against a function of ending stocks. The model is reestimated for each report so that the predictions are based on outof-sample parameter estimates. To account for structural change, the regression model is estimated only using recent data. The ending stocks regressions are estimated using monthly data:

$$
F_{i}=\beta_{1 m}+\beta_{2 m} x_{i}+e_{i} ; i=k, \ldots, m,
$$

where $F_{i}$ is the futures settlement price from the day that the $i$ th WASDE report was released, and $x_{i}$ contains observations of the independent variable, which is the ratio of ending stocks (or yield) and use. We also consider yield rather than ending stocks to determine the potential of using only yield forecasts.

The work of Anderson and Tweeten (1975), Westcott and Hull (1985), Westcott and Hoffman (1999), and Do (2010) provided the inspiration for the use of this model. Their models mostly used a stocks-to-use ratio or a ratio of utilization and ending stocks. They use a ratio in an attempt to correct for structural change in the overall size of the market. Adjemian and Smith (2012) focused on parameter estimation rather than forecasting but also used a stocksto-use ratio. A ratio is not required here because a relatively short time period is used, ${ }^{1}$ but we go ahead and use a stocks-to-use ratio to be consistent with past literature.

The predicted price equation is

$$
\widehat{\text { Price }}_{m+1}=\bar{\beta}_{1 m}+\bar{\beta}_{2 m} x_{m+1},
$$

where $\widehat{\text { Price }}_{m+1}$ is the forecasted price at the next WASDE report release, $x_{m+1}$ is the ending stocks from the next WASDE report, and $m$ is the current report month. The slope coefficient for the rolling regression model is forced to be nonnegative:

$$
\bar{\beta}_{2 m}=\max \left(\hat{\beta}_{2 m}, 0\right)
$$

1 Using the model of Dunn (1975), which uses the inverse of ending stocks alone, gives returns 37\% higher for corn and $73 \%$ higher for soybeans with the weighted average model (Milacek, 2013). 
where $\hat{\beta}_{2 m}$ is the estimated slope coefficient. The intercept coefficient $\bar{\beta}_{1 \mathrm{~m}}$ is calibrated to predict the current report month price without error:

$$
\bar{\beta}_{1 m}=F_{m}-\bar{\beta}_{2 m} x_{m} .
$$

The calibration of the intercept was inspired by a similar approach used by a private market advisory service. The trading rule for day $d$ is

$$
\text { Position }_{m d}=I\left(F_{m d} \leq \widehat{\text { Price }}_{m+1}\right) \text {, }
$$

where $I()$ is an indicator function that is 1 when true and -1 when false, and Position $_{m d}$ is the desired futures position with 1 representing a long position and -1 a short position.

For the moving average method, the slope coefficient for the weighted average model is calculated using a weighted average of the previous year's last regression slope and the slope from the current year. The decision to limit the use of the previous year's regression slope coefficient in this manner is because the model uses only the current year of data. The model's accuracy is low early in the year when there is limited information. Slowly throughout the year the slope is weighted more to the current year than the previous year and in the last month does not use any of the previous slope estimation.

The weighted average model does not provide a price forecast unless two observations are observed in the current WASDE projection year, and the rolling regression model loses some observations at the start of the sample period.

To determine the effectiveness of the models in capturing all possible trading returns, a perfect foresight method was used for comparison. The forecast price of the perfect foresight model is the actual closing price on the day of the next WASDE report.

Note that transaction costs are not included in the calculations. Trades were generated on approximately $10 \%$ of the possible days $(10.02 \%$ for corn and $10.40 \%$ for soybeans). Commission costs should be small for this type of trader such as $\$ 4$ per round turn. Trading is based on closing prices. Liquidity costs would be incurred. With electronic markets, the bid-ask spread is usually one tick (\$12.50) (Wang, Garcia, and Irwin, 2014). So the total costs would be $\$ 16.50$ per trade or $0.33 \phi / \mathrm{bu}$. Incurring this cost $10 \%$ of the time would give costs of $0.033 \phi / \mathrm{bu}$. per day. There could also be additional costs from managing a margin account.

\section{Evaluation Procedure}

The regressions involve corn and soybeans closing prices directly regressed on the ratio of WASDE U.S. ending stocks to use. This section describes the heteroskedasticity adjustment used in calculating the mean of trading returns and our efforts in trying to identify a relationship between trading returns and days until the report. 
The trading returns displayed heteroskedasticity because of increased prices and the subsequent increased volatility of futures prices starting around 2008. An estimated generalized least squares (EGLS) approach was used to estimate mean returns. The first-stage regression includes only an intercept. The log of the squared residuals is regressed on dummy variables for year. The inverse of the exponential of the predicted value from this auxiliary regression gives the predicted variance, which is used to estimate the mean via weighted least squares. Mathematically, the model estimated is

$$
r_{j t}=\mu+\varepsilon_{j t},
$$

where $r_{j t}$ is returns from month $j$ and year $t, \mu$ is the mean, and $\varepsilon_{j t} \sim N\left(0, \sigma_{t}^{2}\right)$. The logarithm transformation is used to reduce the influence of outliers.

We also studied how returns changed as the days from the next report changed. We considered both linear parametric regressions and nonparametric regressions of returns on days to maturity. The nonparametric procedure used was locally weighted regression (LOESS), which fits a separate weighted regression for each data point where observations close to that data point receive greater weight (Cleveland and Devlin, 1988). The weaknesses of the LOESS procedure are that like other nonparametric procedures, it requires a large number of observations to be precise, and it can be time consuming to calculate as local fitting occurs at every observation of the independent variable. No statistical significance was obtained. We concluded that the results were too noisy to make any conclusions regarding how returns changed with days until the report, and so none of these results are included here.

Note also that our results provide the returns from trading a single contract. The value of knowing the WASDE report in advance would depend on the number of contracts traded. The optimal number of contracts to trade would depend on market liquidity, supply/demand of futures contracts, and the trader's ability to tolerate risk. Further, an actual forecast would have errors, which would reduce its value. Thus, the results here provide only a partial picture of the value of knowing the WASDE report in advance.

\section{Results}

The trading returns are reported as averages by WASDE report month and WASDE projection year. The results provide information pertaining to which months would yield the highest returns if the WASDE reports could be anticipated.

\subsection{Regression Coefficients}

The intercepts and slopes of regressions using only data from one entire WASDE projection year are plotted to show the change in the beta coefficients across WASDE projection years. These are displayed in Figures 1 and 2 for corn and 


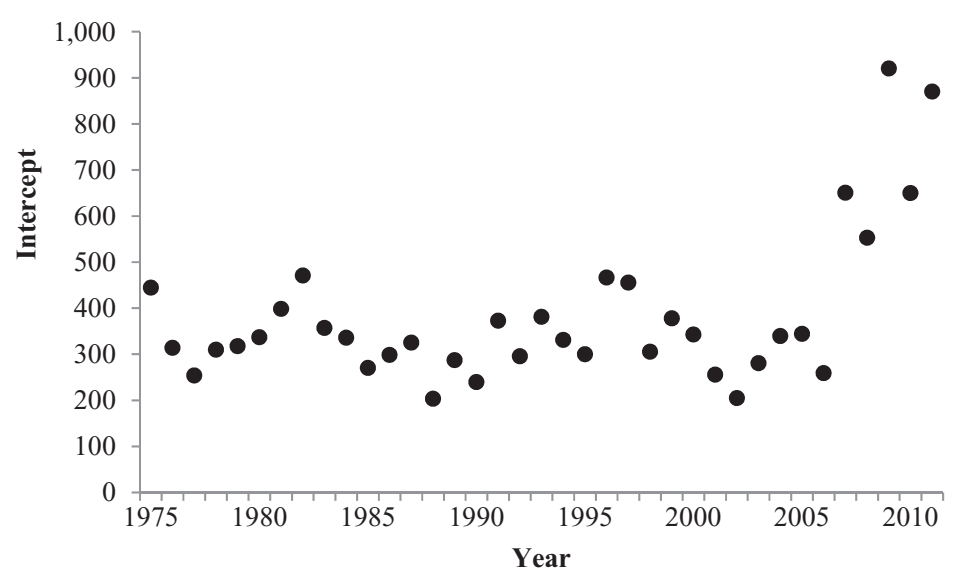

Figure 1. U.S. Corn Final Intercept Coefficient for World Agricultural Supply and Demand Estimates Projection Year Weighted Average Model

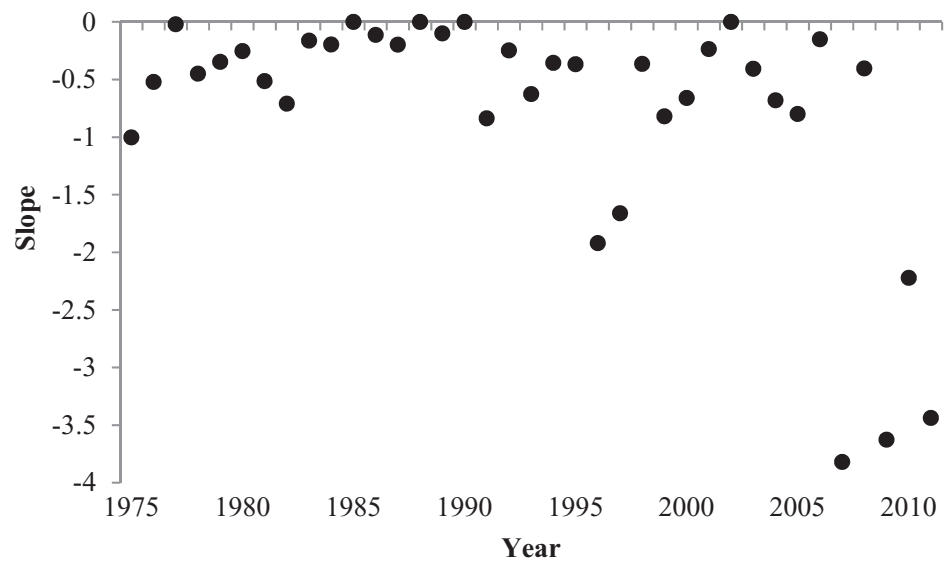

Figure 2. U.S. Corn Final Slope Coefficient for World Agricultural Supply and Demand Estimates Projection Year Weighted Average Model

Figures 3 and 4 for soybeans. The intercept coefficients as seen in Figures 1 and 3 stay relatively constant throughout the sample period. The exception is that intercepts for corn have increased in recent years to capture the increase in prices. Note that these intercepts are not used in forecasting. The intercept used in forecasting is calibrated so that the regression line travels through the price following the most recent report.

The coefficients for slope tend to vary more over time. As the market structure has changed in recent years, the variance of the slope coefficients has become large compared with earlier observations. To combat this, the weighted average model uses a moving average approach that combines estimates with the data 


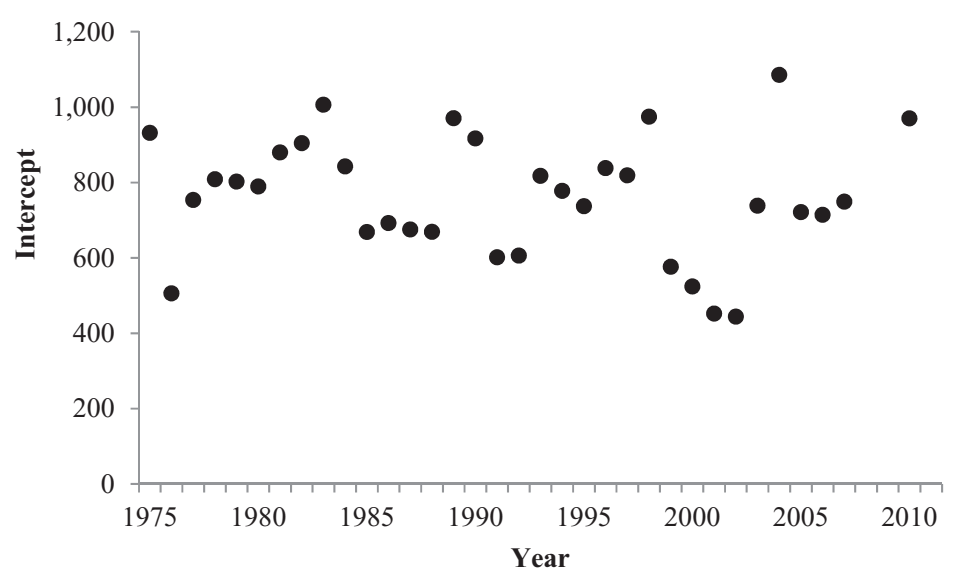

Figure 3. U.S. Soybeans Final Intercept Coefficient of World Agricultural Supply and Demand Estimates Projection Year Weighted Average Model

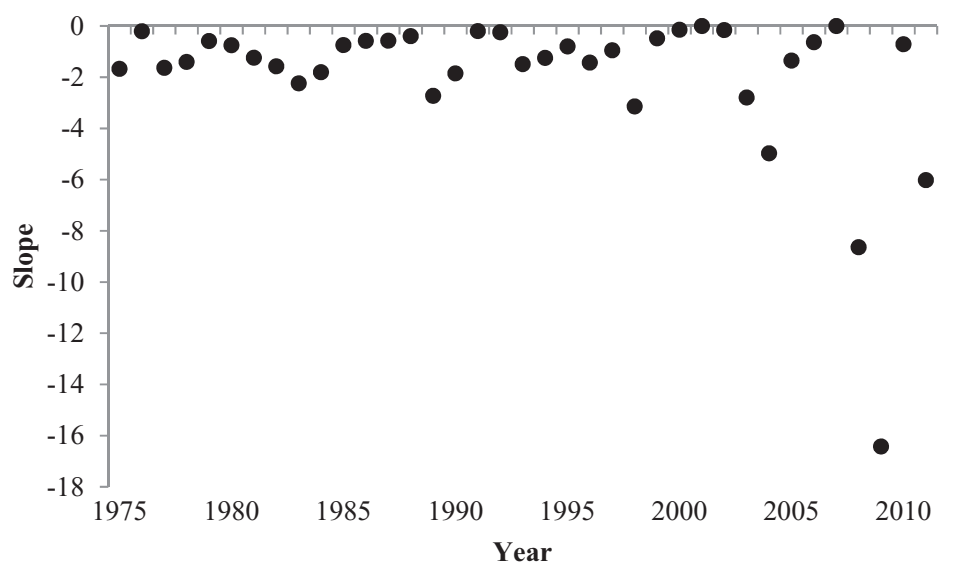

Figure 4. U.S. Soybeans Final Slope Coefficient of World Agricultural Supply and Demand Estimates Projection Year Weighted Average Model

from the year immediately prior and the current estimates. Both corn and soybeans experience a major change in slope coefficients around the year 2008.

These figures show that the market experienced structural changes. The model is able to adjust to these structural changes quickly because of limiting the data used in the calculation of the slope coefficient.

\subsection{Aggregate Results}

From Table 1, the weighted average and rolling regression models show similar returns. The rolling regression results with differing window widths also provide some support for using limited historical data. With the weighted average model, 
Table 1. U.S. Corn and Soybeans Average Daily Returns (cents per bushel)

\begin{tabular}{|c|c|c|c|c|c|c|}
\hline \multirow[b]{2}{*}{ Model } & \multicolumn{3}{|c|}{ Corn } & \multicolumn{3}{|c|}{ Soybeans } \\
\hline & Returns & $t$-Value & Average $R^{2}$ & Returns & $t$-Value & Average $R^{2}$ \\
\hline Weighted average & 0.16 & 2.85 & 0.45 & 0.15 & 1.05 & 0.43 \\
\hline \multicolumn{7}{|l|}{ Rolling regression } \\
\hline \multicolumn{7}{|l|}{ Stocks/use } \\
\hline 12 Months & 0.11 & 2.21 & 0.43 & 0.12 & 0.93 & 0.40 \\
\hline 24 Months & 0.17 & 3.42 & 0.47 & 0.09 & 0.72 & 0.42 \\
\hline 36 Months & 0.17 & 3.49 & 0.47 & 0.20 & 1.54 & 0.40 \\
\hline 48 Months & 0.17 & 3.34 & 0.45 & 0.16 & 1.17 & 0.38 \\
\hline 60 Months & 0.14 & 2.79 & 0.43 & 0.20 & 1.51 & 0.36 \\
\hline \multicolumn{7}{|l|}{ Yield } \\
\hline 12 Months & 0.09 & 1.77 & 0.42 & -0.20 & -1.49 & 0.30 \\
\hline 24 Months & 0.10 & 2.00 & 0.32 & -0.12 & -0.87 & 0.31 \\
\hline 36 Months & 0.07 & 1.30 & 0.33 & -0.05 & -0.40 & 0.28 \\
\hline 48 Months & 0.02 & 0.39 & 0.28 & -0.09 & -0.71 & 0.24 \\
\hline 60 Months & 0.02 & 0.36 & 0.24 & -0.05 & -0.41 & 0.21 \\
\hline
\end{tabular}

Table 2. U.S. Corn and Soybeans Average Daily Returns (cents per bushel) Perfect Foresight Trading Signal

\begin{tabular}{llllllll}
\hline \hline & \multicolumn{3}{c}{ Corn } & & \multicolumn{3}{c}{ Soybeans } \\
\cline { 2 - 4 } \cline { 7 - 8 } Model & Returns & $t$-Value & Average $R^{2}$ & & Returns & $t$-Value & Average $R^{2}$ \\
\hline Weighted average & 1.11 & 20.89 & 0.45 & 2.94 & 21.95 & 0.43 \\
$\begin{array}{l}\text { Rolling regression } \\
\text { Stocks/use }\end{array}$ & 1.02 & 21.29 & 0.47 & 2.77 & 21.66 & 0.40 \\
\hline \hline
\end{tabular}

Note: There are slight differences in the perfect foresight profits because of using different amounts of data for trading.

the average daily return over the entire data set for corn was 0.16 cents per bushel, which is substantially higher than estimated transactions costs of 0.033 cents per bushel. As reported in Table 2, the perfect foresight trading signal made an average daily return of 1.11 cents per bushel. Therefore, the corn model estimation was successful at capturing $14 \%$ of available returns.

Returns per bushel are similar for soybeans and corn, but soybeans have smaller $t$-values because of the higher price of soybeans. Overall, returns are consistently statistically significant for corn, whereas the soybean returns are not. Using yield instead of ending stocks works poorly. Thus, efforts to forecast yield alone are not going to be enough.

The monthly trading returns calculations from Table 3 show that July, September, and October have the highest returns for corn. The perfect foresight trading signal shows that the largest price movements occurred in July and 
Table 3. U.S. Corn Average Daily Returns (cents per bushel) by WASDE Report Month

\begin{tabular}{|c|c|c|c|c|c|c|}
\hline \multirow[b]{2}{*}{$\begin{array}{l}\text { WASDE } \\
\text { Month }\end{array}$} & \multicolumn{3}{|c|}{ Weighted Average Model } & \multicolumn{3}{|c|}{$\begin{array}{l}\text { Rolling Regression Model } \\
36 \text { Months of Data }\end{array}$} \\
\hline & $\begin{array}{l}\text { Number of } \\
\text { Observations }\end{array}$ & Returns & $t$-Value & $\begin{array}{l}\text { Number of } \\
\text { Observations }\end{array}$ & Returns & $t$-Value \\
\hline 1 & 791 & -0.23 & -1.97 & 727 & -0.16 & -1.54 \\
\hline 2 & 636 & 0.32 & 1.92 & 636 & 0.35 & 2.34 \\
\hline 3 & 667 & -0.05 & -0.33 & 625 & -0.08 & -0.58 \\
\hline \multicolumn{7}{|l|}{4} \\
\hline \multicolumn{7}{|l|}{5} \\
\hline 6 & 40 & -0.57 & -1.22 & 655 & 0.08 & 0.50 \\
\hline 7 & 737 & 0.37 & 1.72 & 703 & 0.34 & 1.60 \\
\hline 8 & 838 & -0.01 & -0.05 & 750 & -0.01 & -0.03 \\
\hline 9 & 802 & 0.36 & 2.24 & 718 & 0.50 & 3.19 \\
\hline 10 & 805 & 0.37 & 2.13 & 718 & 0.29 & 1.75 \\
\hline 11 & 797 & 0.20 & 1.34 & 736 & 0.30 & 2.18 \\
\hline 12 & 741 & 0.17 & 1.20 & 699 & 0.12 & 0.91 \\
\hline
\end{tabular}

Note: WASDE, World Agricultural Supply and Demand Estimates.

Table 4. U.S. Corn Average Daily Returns (cents per bushel) by WASDE Report Month for Perfect Foresight Model

\begin{tabular}{|c|c|c|c|c|c|c|}
\hline \multirow[b]{2}{*}{$\begin{array}{l}\text { WASDE } \\
\text { Month }\end{array}$} & \multicolumn{3}{|c|}{ Weighted Average Model } & \multicolumn{3}{|c|}{$\begin{array}{l}\text { Rolling Regression Model } \\
36 \text { Months of Data }\end{array}$} \\
\hline & $\begin{array}{l}\text { Number of } \\
\text { Observations }\end{array}$ & Returns & $t$-Value & $\begin{array}{l}\text { Number of } \\
\text { Observations }\end{array}$ & Returns & $t$-Value \\
\hline 1 & 791 & 0.50 & 4.46 & 727 & 0.48 & 4.56 \\
\hline 2 & 636 & 1.13 & 7.11 & 636 & 1.02 & 7.12 \\
\hline 3 & 667 & 0.87 & 5.70 & 625 & 0.91 & 6.69 \\
\hline \multicolumn{7}{|l|}{4} \\
\hline \multicolumn{7}{|l|}{5} \\
\hline 6 & 40 & 1.07 & 2.40 & 655 & 0.96 & 6.61 \\
\hline 7 & 737 & 1.42 & 6.80 & 703 & 1.39 & 6.77 \\
\hline 8 & 838 & 1.61 & 8.94 & 750 & 1.52 & 8.56 \\
\hline 9 & 802 & 1.19 & 7.61 & 718 & 1.09 & 7.21 \\
\hline 10 & 805 & 1.23 & 7.28 & 718 & 1.09 & 6.71 \\
\hline 11 & 797 & 1.02 & 7.26 & 736 & 0.87 & 6.53 \\
\hline 12 & 741 & 0.99 & 7.25 & 699 & 0.91 & 6.92 \\
\hline
\end{tabular}

Note: WASDE, World Agricultural Supply and Demand Estimates.

August (Table 4). Pollination occurs in this time period, and that is a critical period of growth for corn. Mattos and Silveira (2016) also found the effects of crop reports were largest in the months preceding the beginning of harvest. The perfect foresight model shows that for corn the largest opportunity for returns is toward the end of the growing season and on into harvest in the fall. 
Table 5. U.S. Soybean Average Daily Returns (cents per bushel) by WASDE Report Month

\begin{tabular}{|c|c|c|c|c|c|c|}
\hline \multirow[b]{2}{*}{$\begin{array}{l}\text { WASDE } \\
\text { Month }\end{array}$} & \multicolumn{3}{|c|}{ Weighted Average Model } & \multicolumn{3}{|c|}{$\begin{array}{l}\text { Rolling Regression Model } \\
36 \text { Months of Data }\end{array}$} \\
\hline & $\begin{array}{l}\text { Number of } \\
\text { Observations }\end{array}$ & Returns & $t$-Value & $\begin{array}{l}\text { Number of } \\
\text { Observations }\end{array}$ & Returns & $t$-Value \\
\hline 1 & 791 & -0.18 & -0.57 & 705 & 0.28 & 0.86 \\
\hline 2 & 667 & 0.28 & 0.73 & 646 & 0.39 & 1.00 \\
\hline 3 & 675 & -0.16 & -0.37 & 642 & -0.21 & -0.49 \\
\hline \multicolumn{7}{|l|}{4} \\
\hline 5 & 11 & -2.14 & -0.43 & 17 & 0.57 & 0.31 \\
\hline 6 & 21 & 0.14 & 0.09 & 634 & -0.46 & -1.20 \\
\hline 7 & 712 & 0.24 & 0.47 & 704 & 0.28 & 0.54 \\
\hline 8 & 837 & -0.25 & -0.54 & 750 & 0.01 & 0.03 \\
\hline 9 & 802 & 0.77 & 1.86 & 718 & 0.84 & 2.01 \\
\hline 10 & 804 & -0.14 & -0.35 & 717 & -0.07 & -0.17 \\
\hline 11 & 803 & 0.48 & 1.26 & 722 & 0.79 & 2.07 \\
\hline 12 & 678 & 0.33 & 0.84 & 678 & 0.07 & 0.18 \\
\hline
\end{tabular}

${ }^{a}$ The rolling regression results differ little by how many months are included as shown in Table 1. We elected to report 36 months for soybeans because it had slightly higher returns than 24 months.

Note: WASDE, World Agricultural Supply and Demand Estimates.

Soybean results are similar to results for corn. With the weighted average model, the average daily return over the entire data set was 0.15 cents per bushel (Table 1). The perfect foresight model returned an average daily return of 2.94 cents per bushel (Table 2). Therefore, the model for soybeans captured only $5 \%$ of the total available returns. The model captured less available returns than the corn model, which could be attributable to the soybean price being more influenced by world events. Also, soybeans have more substitutes than does corn. Thus, ending stocks may not reflect as much information for soybeans as they do for corn.

For soybeans, Table 5 shows that the only months with statistically significant returns are September and November. Ignoring the small sample in May, for soybeans the perfect foresight shown in Table 6 showed the largest potential returns in March, July, and August. The perfect foresight models for soybeans do not show a strong seasonal pattern by month. Work by Isengildina-Massa et al. (2008a, 2008b) and Adjemian (2012) showed the importance of the January crop reports because of the information on harvest data contained in them, but we do not find such a result with our approach. Unlike corn, the soybean market is not influenced as heavily by weather and crop conditions during the growing season. Soybeans are grown with varying maturities and do not have a well-defined critical growth period like the time of pollination for corn. Also, U.S. corn is less important in the world market for soybeans than it is in the world market for corn (USDA, Economics Research Service, 2016a, 2016b). 
Table 6. U.S. Soybean Average Daily Returns (cents per bushel) by WASDE Report Month for Perfect Foresight Model

\begin{tabular}{|c|c|c|c|c|c|c|}
\hline \multirow[b]{2}{*}{$\begin{array}{l}\text { WASDE } \\
\text { Month }\end{array}$} & \multicolumn{3}{|c|}{ Weighted Average Model } & \multicolumn{3}{|c|}{$\begin{array}{l}\text { Rolling Regression Model } \\
36 \text { Months of Data }\end{array}$} \\
\hline & $\begin{array}{l}\text { Number of } \\
\text { Observations }\end{array}$ & Returns & $t$-Value & $\begin{array}{l}\text { Number of } \\
\text { Observations }\end{array}$ & Returns & $t$-Value \\
\hline 1 & 791 & 1.97 & 6.27 & 705 & 1.74 & 5.48 \\
\hline 2 & 667 & 2.67 & 7.15 & 646 & 2.70 & 7.17 \\
\hline 3 & 675 & 3.41 & 8.52 & 642 & 3.29 & 8.14 \\
\hline \multicolumn{7}{|l|}{4} \\
\hline 5 & 11 & 7.95 & 1.84 & 17 & 0.57 & 0.31 \\
\hline 6 & 21 & 1.29 & 0.84 & 634 & 2.62 & 7.04 \\
\hline 7 & 712 & 3.32 & 6.69 & 704 & 3.18 & 6.43 \\
\hline 8 & 837 & 3.57 & 7.88 & 750 & 3.24 & 6.98 \\
\hline 9 & 802 & 2.62 & 6.44 & 718 & 2.49 & 6.08 \\
\hline 10 & 804 & 2.85 & 7.09 & 717 & 2.58 & 6.24 \\
\hline 11 & 803 & 3.10 & 8.48 & 722 & 2.99 & 8.09 \\
\hline 12 & 678 & 3.02 & 7.96 & 678 & 2.98 & 7.91 \\
\hline
\end{tabular}

Note: WASDE, World Agricultural Supply and Demand Estimates.

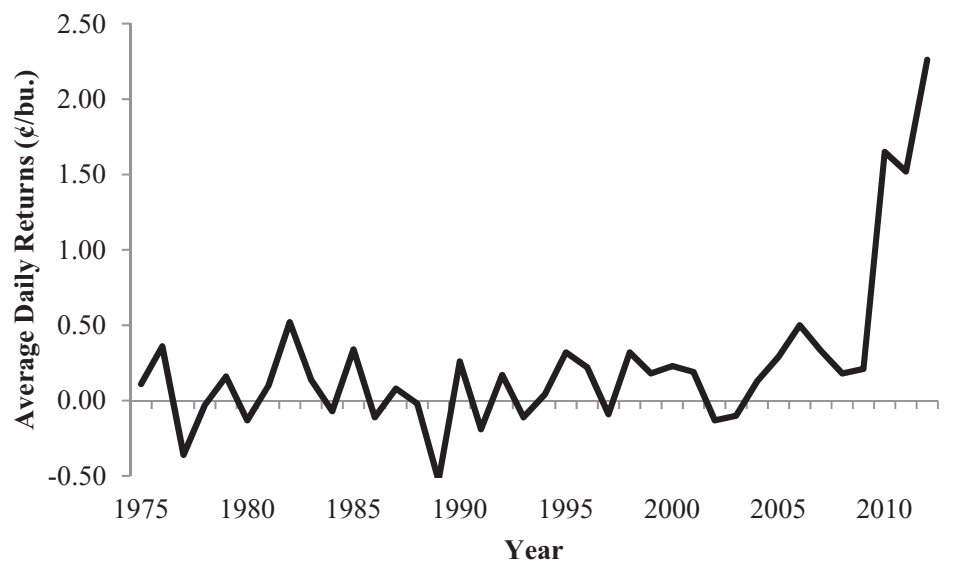

Figure 5. U.S. Corn Average Daily Returns (cents per bushel) for Weighted Average Model by Year

\subsection{Returns across Years}

Yearly returns are calculated to study structural change and are displayed in Figures 5 and 6. Sudden changes in market structure because of policy changes, the economic climate, or weather patterns can dramatically affect the returns from a trading model. An increase in slope coefficients from the weighted average model in Figures 2 and 4 coincides with an increase in the volatility of average daily returns. The volatility of recent returns has been high, with the corn model 


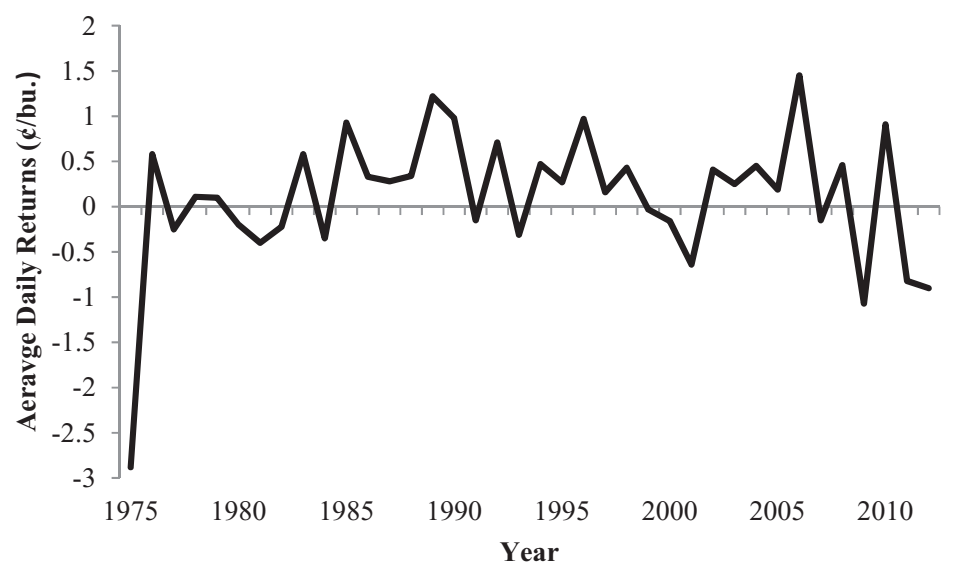

Figure 6. U.S. Soybeans Average Daily Returns (cents per bushel) for Weighted Average Model by Year

doing well in recent years (Figure 5), whereas the soybean model is less consistent (Figure 6).

\section{Summary and Conclusions}

This research determines the potential trading returns from perfectly predicting WASDE reports on a daily basis for U.S. corn and soybeans. Any WASDE report forecast available to a trader would have errors, and so the trading returns here represent an upper bound. The WASDE reports used include projections that span from May to March of the next calendar year.

To calculate returns, two models are used to forecast price on the day of a report release. To limit the effect of structural change, one model uses a weighted average to calculate the slope coefficient on the model regression. New regressions are developed for every month, and the intercept coefficient is calibrated so that the most recent month's price is estimated without error. Then, a trading signal determines the buy-sell position depending on whether the previous day's closing price was above or below the price forecast. With the rolling regression model, the number of observations included in the regression is varied over 12, 24, 36, 48, and 60 observations. Similar to the weighted average model, the rolling regression model produces a price forecast that is used to determine the long/short position.

The returns from the model calculations are weighted using EGLS. This accounts for periods of increased volatility to make the returns comparable across the entire data set. Without this weighting, recent market activity would overshadow previous market conditions.

Corn and soybeans returns do not have the same pattern across WASDE report months. Corn experienced increased returns in the summer months. This 
is attributable to critical growth periods during the hot summer months, and the weather conditions during this time greatly affect the potential yield of the harvested crop. Returns were also higher in the fall, which could be attributable to information about actual yields becoming available. One observation that can be made is that returns are highest when the crop is at critical growth periods and when harvest information becomes available.

Evidence of structural change is observed for corn and soybeans when the average daily returns were sorted by the WASDE projection year. Increased returns and increased price volatility occur around the years 2007 and 2008. To limit the effect of structural change, the price forecasting models were estimated using only recent data.

As expected, it would be valuable to know the WASDE report in advance, but positive returns would by no means be guaranteed. Although even 31 calendar days away from the report release has positive returns, the returns are noisy, and traders would be subject to extreme risk because of the influence of other information sources causing market movement throughout the month. Knowing only ending stocks does not provide enough predictive power for a forecasted price to capture a majority of the market movement. Price forecasting models with more variables may be needed to account for market movement as ending stocks account for a small, yet very important portion of this movement.

\section{References}

Adjemian, M.K. "Quantifying the WASDE Announcement Effect." American Journal of Agricultural Economics 94,1(2012):238-56.

Adjemian, M.K., and A. Smith. "Using USDA Forecasts to Estimate the Price Flexibility of Demand for Agricultural Commodities." American Journal of Agricultural Economics 94,4(2012):978-95.

Anderson, K.B., and L. Tweeten. "A Simplified Procedure to Predict Seasonal Average Wheat and Feed Grain Price." Oklahoma Current Farm Economics 48,3(1975):3-8.

Cleveland, W.S., and S.J. Devlin. "Locally Weighted Regression: An Approach to Regression Analysis by Local Fitting." Journal of the American Statistical Association 83,403(1988):596-610.

Do, T. “World and United States Wheat Supply, Demand, Prices and a Pricing Model.” Master's thesis, Department of Agricultural Economics, Oklahoma State University, Stillwater, 2010.

Dorfman, J.H., and B. Karali. "A Nonparametric Search for Information Effects from USDA Reports.” Journal of Agricultural and Resource Economics 40,1(2015):124-43.

Dunn, J. "Another Wheat Price and Carryover Stocks Equation." Current Farm Economics. Stillwater: Oklahoma State University, 1975, pp. 4-9.

Fortenbery, T.R., and D.A. Sumner. "The Effects of USDA Reports in Futures and Options Markets.” Journal of Futures Markets 13,2(1993):157-73.

Irwin, S., and D. Good. "The Relationship between Stocks-to-Use and Corn and Soybean Prices: An Alternative View.” farmdoc daily 6(April 2016):66. Internet site: http:// farmdocdaily.illinois.edu/2016/04/relationship-between-stock-to-use-and-prices.html (Accessed March 5, 2017). 
Isengildina, O., S.H. Irwin, and D.L. Good. “Are Revisions to USDA Crop Production Forecasts Smoothed?” American Journal of Agricultural Economics 88,4(2006a):1091-104.

. "The Value of USDA Situation and Outlook Information in Hog and Cattle Markets." Journal of Agricultural and Resource Economics 31,2(2006b):262-82.

Isengildina-Massa, O., S.H. Irwin, D.L. Good, and J.K. Gomez. "The Impact of Situation and Outlook Information in Corn and Soybean Futures Markets: Evidence from WASDE Reports." Journal of Agricultural and Applied Economics 40,1(2008a):89-109.

- "Impact of WASDE Reports on Implied Volatility in Corn and Soybean Markets." Agribusiness 24,4(2008b):473-90.

Mallory, M.L., S.H. Irwin, and D.J. Hayes. "How Market Efficiency and the Theory of Storage Link Corn and Ethanol Markets.” Energy Economics 34,6(2012):2157-66.

Mattos, F.L., and R.L.F. Silveria. "Futures Price Response to Crop Reports in Grain Markets." Journal of Futures Markets 35,10(2016):923-42.

McKenzie, A.M. "Pre-harvest Price Expectations for Corn: The Information Content of USDA Reports and New Crop Futures." American Journal of Agricultural Economics 90,2(2008):351-66.

Milacek, T.T. "How Much Would It Be Worth to Know the WASDE Report in Advance?" Master's thesis, Department of Agricultural Economics, Oklahoma State University, Stillwater, 2013.

Milonas, N.T. “The Effects of USDA Crop Announcements on Commodity Prices.” Journal of Futures Markets 7,5(1987):571-89.

Sumner, D.A., and R.A.E. Mueller. "Are Harvest Forecasts News? USDA Announcements and Futures Market Reactions.” American Journal of Agricultural Economics 71,1(1989):18.

U.S. Department of Agriculture (USDA). Agricultural Supply and Demand Estimates. September 17, 1973. Internet site: http://usda.mannlib.cornell.edu/usda/waob/wasde/ /1970s/1973/wasde-09-17-1973.pdf (Accessed March 5, 2017).

U.S. Department of Agriculture, Economics Research Service. “Corn.” 2016a. Internet site: http://www.ers.usda.gov/topics/crops/corn/trade.aspx (Accessed July 21, 2016).

—. "Soybeans and Oil Crops." 2016b. Internet site: http://www.ers.usda.gov/topics/crops/ soybeans-oil-crops/trade.aspx (Accessed July 21, 2016).

Vogel, F.A., and G.A. Bange. Understanding USDA Crop Forecasts. Washington DC: U.S. Department of Agriculture, National Agricultural Statistics Service and Office of the Chief Economist, World Agricultural Outlook Board, Miscellaneous Publication No. 1554, 1999.

Wang, X., P. Garcia, and S.H. Irwin. "The Behavior of Bid-Ask Spreads in the Electronically-Traded Corn Futures Market.” American Journal of Agricultural Economics 96,2(2014):557-77.

Westcott, P.C., and L.A. Hoffman. Price Determination for Corn and Wheat: The Role of Market Factors and Government Programs. Washington, DC: U.S. Department of Agriculture, Economic Research Service, Technical Bulletin No. 1878, 1999.

Westcott, P.C., and D.B. Hull. "Relationships between Quarterly Grain Prices and Stocks." Proceedings of the NCR-134 Conference on Applied Commodity Price Analysis, Forecasting and Market Risk Management, Chicago, IL. 1985. Internet site: http:// www.farmdoc.illinois.edu/nccc134/conf_1985/pdf/confp14-85.pdf (Accessed March 5, 2017). 